\title{
Linking Smoking, Coffee, Urate, and Parkinson's Disease - A Role for Gut Microbiota?
}

\author{
Filip Scheperjans ${ }^{\mathrm{a}, *}$, Eero Pekkonen ${ }^{\mathrm{a}}$, Seppo Kaakkola ${ }^{\mathrm{a}}$ and Petri Auvinen ${ }^{\mathrm{b}}$ \\ ${ }^{a}$ Department of Neurology, Helsinki University Hospital and Department of Clinical Neurosciences (Neurology), \\ University of Helsinki, Helsinki, Finland \\ ${ }^{\mathrm{b}}$ Institute of Biotechnology, DNA Sequencing and Genomics Laboratory, University of Helsinki, Helsinki, Finland
}

\begin{abstract}
While the etiology and pathogenesis of Parkinson's disease (PD) is still obscure, there is evidence for lifestyle factors influencing disease risk. Best established are the inverse associations with smoking and coffee consumption. In other contexts there is evidence that health effects of lifestyle factors may depend on gut microbiome composition. Considering the gastrointestinal involvement in PD, it was recently speculated, that the associations between smoking, coffee, and PD risk could be mediated by gut microbiota. Here we review such a possible mediatory role of gut microbiota taking into account recent findings on microbiome composition in PD and extending the scope also to urate.
\end{abstract}

Keywords: Gut-brain axis, risk factors, non-motor symptoms, gut motility, constipation, nicotine, caffeine, inflammation, gut permeability, dietary fiber

\section{RELATIONS OF SMOKING, COFFEE CONSUMPTION, AND SERUM URATE LEVELS TO PD RISK AND THEIR PROPOSED MECHANISMS}

A history of smoking reduces the risk of PD by about $36 \%-50 \%$ and there is an inverse dose-response relationship while for coffee consumption the risk reduction is about $33 \%[1,2]$. The exact mechanisms behind these associations are not known, but cigarette smoke and coffee contain possibly neuroprotective compounds such as nicotine and caffeine, respectively $[1,3-5]$. Coffee is also rich in potentially neuroprotective polyphenols [6].

On the molecular level, nicotine is a potent agonist to nicotinic acetylcholine receptors (nAChR) whereas caffeine is a nonselective adenosine receptor antagonist. It has been suggested that mainly nAChRs and

\footnotetext{
*Correspondence to: Filip Scheperjans, Department of Neurology, Helsinki University Hospital, Haartmaninkatu 4, 00290 Helsinki. Tel.: +358 9 4711; Fax: +358 9 47174089; E-mail: filip.scheperjans@hus.fi.
}

Adenosine $\mathrm{A}(2 \mathrm{~A})$ receptors mediate the neuroprotective effects of nicotine and caffeine, respectively $[3,4,7,8]$. Another mechanism could be prevention of misfolding and fibril formation of $\alpha$-synuclein $[9,10]$. It is still unclear whether these molecules are solely responsible for the observed risk reduction. Challenging common interpretations related to neuroprotection, a recent study suggested that the reduced risk of PD in smokers could instead be explained by reverse causation in terms of a greater ease of smoking cessation in the prodromal phase of PD related to the loss of nicotinic rewards [11]. More generally it has been speculated that personality traits associated with PD, in particular low sensation seeking, could be the cause for reduced cigarette smoking and caffeine consumption in subjects later diagnosed with PD [12].

Although the number of publications addressing urate levels and PD risk is rather small, the results have been relatively consistent $[2,13]$. These studies indicate a protective effect of high versus low serum uric acid levels with a risk reduction of $33 \%$ [13]. 
Furthermore, urate levels were inversely associated with disease progression. Since urate is a powerful antioxidant and oxygen radical scavenger it has been speculated that its protective effect against PD is based on a reduction of oxidative stress [13].

\section{THE GUT AND ITS MICROBIOTA IN PD}

In recent years, one important focus of PD research has been on gut related pathology, pathophysiology, and symptoms. Gastrointestinal dysfunction, in particular constipation, affects up to $80 \%$ of PDpatients and idiopathic constipation is one of the strongest risk-factors for PD [1, 14]. In PD, prolonged intestinal transit time and constipation are associated with $\alpha$-synuclein accumulation and neurodegenerative changes in the enteric nervous system [15]. Furthermore, there are signs of local inflammation, oxidative stress, and increased mucosal permeability [16, 17]. These changes can be found in earliest stages of PD, sometimes years before the appearance of motor symptoms, lending support to the hypothesis that environmental factors relevant for PD pathogenesis might act primarily via the gut $[14,18-21]$. One proposed pathophysiological pathway in this context is the induction of intestinal mucosal inflammation leading to accumulation of misfolded $\alpha$-synuclein in enteric nerves which thereafter could act in a prion-like fashion leading to propagation of the neuropathological changes via autonomic connections to the central nervous system [16, 17, 22].

The human gut is home to $1-2 \mathrm{~kg}$ of bacteria, contains 10-times more microbial cells than human cells and these microbes carry approximately 100-200times more protein coding genes than the human genome [23]. Gut microbiota influence the immune system and the absorption of nutrients, vitamins, medications, and toxic compounds [24-28]. Changes in gut microbiota have been found in a multitude of human diseases fuelling hope for better understanding and new treatments for these disorders [29]. There is an intense bidirectional interaction between gut microbiota and the nervous system influencing brain activity, behavior, as well as levels of neurotransmitter receptors and neurotrophic factors [30-34]. Recently, in a case-control study we identified alterations of gut microbiota in $\mathrm{PD}$, in particular a reduced abundance of bacteria from the Prevotellaceae family [35]. Prevotella are mucous degrading diet sensitive bacteria. Some studies have reported an association between higher Prevotella abundance and a less developed mucous layer and a higher sensitivity to experimentally induced colitis as well as associations with rheumatic diseases [36-39]. This, however, is in contrast to the strong evidence that a diet rich in fiber, fruit, and vegetables is associated with higher intestinal Prevotellaceae abundance, lower risk for the development of inflammatory bowel disease, and higher production of health promoting short-chain fatty acids (SCFAs) [40-42]. Furthermore, several studies have demonstrated lower Prevotella abundance in type 1 diabetes and it has been suggested that this could be related to impairment of mucin synthesis and barrier function $[43,44]$. We found no evidence for decreased Bifidobacteria levels in PD [45]. However, our analyses were restricted to the taxonomic family level and therefore do not exclude alterations at genus or species levels [35]. In our study, the abundance of Enterobacteriaceae bacteria was related to the severity of postural instability and gait difficulty. The relevance of these bacterial families for PD is supported by previous reports of colonic mucosal invasion by coliform bacteria, increased mucosal permeability, and increased systemic endotoxin exposure in PD subjects [16].

\section{RELATIONS BETWEEN SMOKING AND GUT MICROBIOTA AND THEIR RELEVANCE FOR GUT INFLAMMATION AND PERMEABILITY}

The best documented gastrointestinal effect of smoking, after carcinogenesis, is immunomodulation by nicotine and carbon monoxide [46, 47]. Smoking increases the risk for and severity of Crohn's disease, but the opposite is seen with respect to ulcerative colitis [48]. There is also some evidence for an increased risk for gastric ulcers and dose dependent effects on gut motility $[49,50]$. Effects of cigarette smoke on intestinal barrier function seem to differ between gut segments. After cigarette smoke exposure mice showed impairment of the intestinal barrier and bacterial translocation in the small bowel, but unchanged or even improved barrier function in the large bowel [51, 52]. Improved gut barrier function has been reported also in human subjects [53]. Overall, the effect of smoke and its constituents on the small bowel seems deleterious, increasing susceptibility for inflammatory stimuli. Instead, in the colon, both pro- and anti-inflammatory effects are seen, possibly depending on genetic and environmental factors and cytokine environment [47]. Importantly, smoking also seems to have an effect on gut microbiome 
composition. Not only do smokers have higher abundance of Bacteroides/Prevotella in their feces, but this abundance decreases together with that of Proteobacteria after smoking cessation while levels of Firmicutes and Actinobacteria increase [54, 55]. Furthermore, improvements in colonic barrier function and inflammation caused by cigarette smoke were associated with a decrease of Ruminococcus albus and Enterobacteriaceae [52]. Less smoking in PD subjects alone does, however, not explain decreased Prevotellaceae and increased Ruminococcaceae levels since these findings were independent of smoking status [35]. Reduced inflammation and gut permeability combined with a decrease in Enterobacteriaceae abundance after smoke exposure fits to the co-occurrence of Escherichia coli invasion, mucosal inflammation, and permeability increase reported in PD [16, 52]. Even the abovementioned hypothesis of the inverse association of smoking and PD being explained by certain personality traits or loss of nicotine reward is not in contradiction with an involvement of gut microbiota $[11,12]$. The gut microbiome influences reward seeking behavior and could therefore influence the propensity to smoke [56].

In summary, smoking affects gut microbiome composition and this seems to go along with improved barrier function and anti-inflammatory effects in the colonic mucosa. It remains to be established whether these simultaneous changes are causally related to each other and eventually to PD. Also a possible reverse effect of gut microbiota on smoking propensity and its relevance for PD is an interesting field for future studies.

\section{THE TRIANGLE OF COFFEE, GUT MOTILITY, AND MICROBIOTA - IS IT RELEVANT FOR GUT DYSFUNCTION IN PD?}

Regarding coffee the best documented effects on the gastrointestinal tract are promotion of gastro-oesophageal reflux, stimulation of gallbladder contraction and an increase of colonic motor activity [57]. Distal colonic motility increases as early as 4 minutes after coffee ingestion [58]. These effects are unlikely mediated by caffeine, instead an indirect action on the colon mediated by neural mechanisms or gastrointestinal hormones has been suspected. Coffee consumption is also inversely associated with the prevalence of self-reported constipation [59]. Some effects of coffee might be related to constituents such as alkaloids, phenolic compounds, fibers, and minerals. Dietary fiber contained in coffee has marked effects on gut microbiota. It is rapidly metabolized into SCFAs and causes a marked expansion of Bacteroides/ Prevotella bacteria [60]. In vivo, one study found a decrease of Bacteroides after coffee consumption while another did not find changes of Bacteroides/ Prevotella [61, 62]. This could, however, indicate an expansion of Prevotella bacteria since their abundance is inversely associated with that of Bacteroides [63]. In vivo, coffee caused an increase of anti-inflammatory Bifidobacteria and a decrease of Clostridium spp. and Escherichia coli that invade the gut mucosa in PD [16, 61, 62, 64].

It is important to consider that alterations in gut motility, as found in $\mathrm{PD}$, and gut microbiome composition could be independently related to each other. Decreased Prevotella abundance and, more consistently, a decreased abundance of Bifidobacteria were found in constipated subjects [65-67]. In our recent study, however, we did not find such associations. Instead, constipation was associated positively with abundance of Verrucomicrobiaceae and negatively with levels of Bradyrhizobiaceae [35]. Apparently, constipation itself may predispose to microbiome alterations, increased mucosal permeability, and inflammation [66].

In summary, there seem to be complex interrelations between coffee and more generally the amount and type of consumed polysaccharides, gastrointestinal transit, and microbiome composition that are not well understood, but may have connections to mucosal permeability and inflammation [68]. All these domains are known to be altered also in PD and in the few studies available, microbiome changes induced by coffee somewhat resemble what has been seen in the microbiome of control subjects versus PD patients [16, 35]. Although direct evidence for the relevance of these interactions for phenomena seen in PD is still missing, there is an intriguing framework for hypothesis generation.

\section{GUT MICROBIOTA ARE RELATED TO SERUM URATE LEVELS, BUT LITTLE IS KNOWN ABOUT LOCAL EFFECTS IN THE GUT}

Although relatively scarce, data regarding the relationship between gut microbiota and urate metabolism mostly corroborate recent microbiome findings and lower urate levels in PD. In particular, it has been 
Table 1

Summary table of bacterial taxa that have been reported to show altered abundances in the colon or feces in relation to PD and/or PD risk modifiers (includes in vitro as well as in vivo studies on humans and animal models)

\begin{tabular}{|c|c|c|c|c|c|c|}
\hline Taxon & $\begin{array}{l}\text { Abundance in } \\
\text { PD vs. Controls }\end{array}$ & $\begin{array}{l}\text { Effect of } \\
\text { smoking }\end{array}$ & $\begin{array}{l}\text { Effect of } \\
\text { coffee }\end{array}$ & $\begin{array}{l}\text { Association with } \\
\text { higher urate levels }\end{array}$ & Remarks & References \\
\hline Bacteroidetes & & & & & Together with Firmicutes constitute over $90 \%$ of distal gut microbiota. & [72] \\
\hline Prevotellaceae & $\downarrow$ & & & & $\begin{array}{l}\text { Positively associated with levels of the neuroprotective gut hormone Ghrelin. Increased } \\
\text { abundance reported in ankylosing spondylitis. }\end{array}$ & {$[35,39,73]$} \\
\hline Prevotella & & $?$ & $\uparrow ?$ & $\uparrow$ & $\begin{array}{l}\text { Breakdown of carbohydrates and mucous. Abundance correlates with fiber, fruit, and } \\
\text { vegetable consumption and is inversely related to Bacteroides abundance. Prevotella } \\
\text { copri has been associated with rheumatoid arthritis. Low abundance has been associated } \\
\text { with autism and type I diabetes. }\end{array}$ & $\begin{array}{l}{[36-38,40,} \\
42-44,54,55 \\
60-63,69,74]\end{array}$ \\
\hline \multicolumn{7}{|l|}{ Bacteroidaceae } \\
\hline Bacteroides & & $?$ & $\downarrow$ & $\downarrow$ & $\begin{array}{l}\text { Abundance positively associated with protein- and animal-fat-rich "western" diet and } \\
\text { inversely related to Prevotella abundance. }\end{array}$ & $\begin{array}{l}{[40,54,55} \\
60-63]\end{array}$ \\
\hline Firmicutes & & $\downarrow$ & & & Together with Bacteroidetes constitute over $90 \%$ of distal gut microbiota. & [72] \\
\hline Ruminococcaceae & $\uparrow$ & & & & Higher abundance was not PD specific in confounder adjusted analysis. & [35] \\
\hline Ruminococcus albus & & $\downarrow$ & & & Obtain nutrients by breaking down cellulose. Ferments glucose and xylose. & [52] \\
\hline Lactobacillaceae & $\uparrow$ & & & & $\begin{array}{l}\text { May perform several beneficial roles including immunomodulation, interference with } \\
\text { enteric pathogens, and maintenance of healthy intestinal microflora. Inversely } \\
\text { associated with levels of the neuroprotective gut hormone Ghrelin. Modulate activity of } \\
\text { enteric neurons. }\end{array}$ & {$[35,73,75,76]$} \\
\hline Clostridiaceae (IV) & $\uparrow$ & & & & $\downarrow$ in confounder adjusted analysis & [35] \\
\hline Clostridium & & & $\downarrow$ & & $\begin{array}{l}\text { Around } 100 \text { species that include common free-living bacteria, as well as important } \\
\text { pathogens. }\end{array}$ & [62] \\
\hline Proteobacteria & & $\uparrow$ & & & & {$[54,55]$} \\
\hline Enterobacteriaceae & & $\downarrow$ & & & $\begin{array}{l}\text { A large family of bacteria that includes, along with many harmless symbionts, also } \\
\text { familiar pathogens. Abundance associated with PIGD symptoms in PD patients. } \\
\text { Increased abundance reported in autistic children. }\end{array}$ & {$[35,52,77]$} \\
\hline Escherichia coli & & & $\downarrow$ & & $\begin{array}{l}\text { Includes hundreds of different strains that are involved in food digestion, but some can } \\
\text { cause intestinal and extra-intestinal infections. Invade gut mucosa in PD. }\end{array}$ & {$[16,62]$} \\
\hline Bradyrhizobiaceae & $\uparrow$ & & & & Was negatively related to constipation in PD microbiota study. & [35] \\
\hline $\begin{array}{l}\text { Actinobacteria } \\
\text { Bifidobacteriaceae }\end{array}$ & & $\downarrow$ & & & & {$[54,55]$} \\
\hline Bifidobacterium & & & $\uparrow$ & & $\begin{array}{l}\text { Ubiquitous, endosymbiotic inhabitants of the gastrointestinal tract, vagina, and mouth. } \\
\text { Some strains are considered important probiotics. May exert beneficial health effects } \\
\text { such as immune modulation, inhibition of pathogens, and bioconversion of dietary } \\
\text { compounds into bioactive molecules. Improve gut mucosal barrier and lower levels of } \\
\text { lipopolysaccharide in the intestine. }\end{array}$ & {$[61,62,64,78]$} \\
\hline \multicolumn{7}{|c|}{ 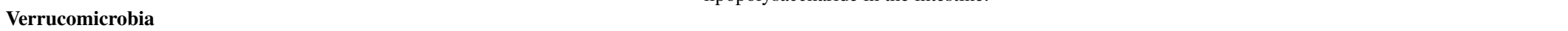 } \\
\hline Verrucomicrobiaceae & $\uparrow$ & & & & Was positively related to constipation in PD microbiota study. & [35] \\
\hline
\end{tabular}

Taxonomic levels: Phylum, Family, Genus/Species. $\uparrow / \downarrow=$ Direction of bacterial abundance difference related to the respective factor ? = Alterations of abundance have been reported, but reports are inconclusive since Bacteroides/Prevotella were analyzed as one group although abundances of these genera are usually inversely related to each other. 


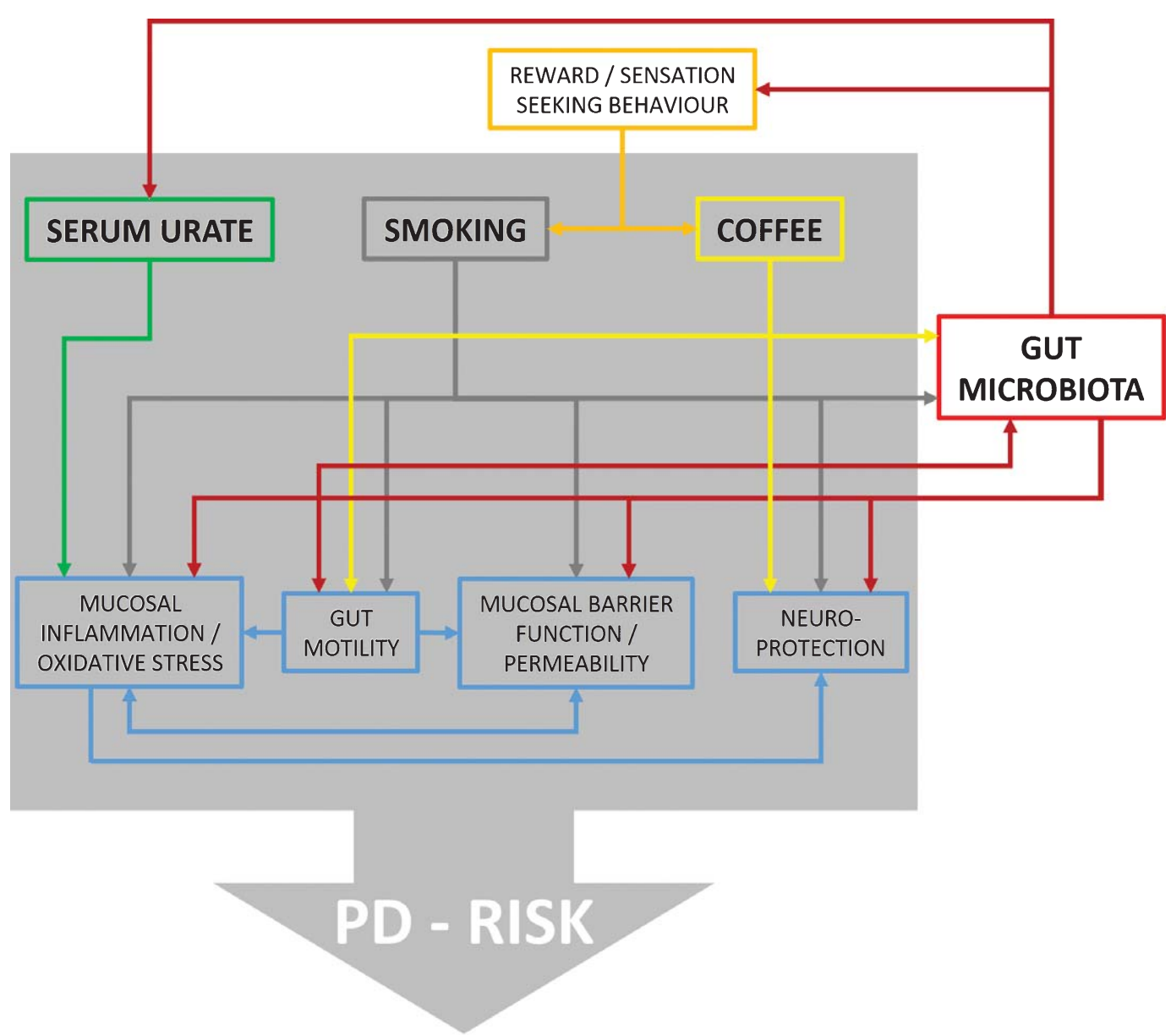

Fig. 1. Flow chart illustrating reported effects between urate, smoking, coffee, and different physiological domains with possible relevance for PD risk. Furthermore, it is shown which of these factors are also related to changes in gut microbiota providing ground for interactions. However, at present direct evidence for such interactions is missing and information is derived from in vitro as well as in vivo studies on humans and animal models.

shown that the Prevotella dominated enterotype, which seems to be underrepresented in PD subjects, is associated with higher serum uric acid levels [35, 69]. This could be due to a lower activity of hydroxyisourate hydrolase, which is involved in the conversion of uric acid to allantoin (intestinal uricolysis) [69]. With respect to effects of uric acid on gut physiology, mainly oxidative stress and inflammation have been studied, but results are heterogeneous and cannot necessarily be extrapolated to systemic or central nervous compartments. In plasma, uric acid accounts for about half of the antioxidant capacity, while in colonic biopsies, it has only a small contribution [70]. In the gut mucosa, xanthine oxidase is upregulated in response to oxidative stress [52]. However, in addition to producing uric acid, this enzyme also produces reactive oxygen species. Therefore, an increase in uric acid production may actually go along with increases in oxidative stress and inflammation, at least in the gut mucosa [70, 71]. The Prevotella enteroype produces high amounts of the anti-inflammatory SCFA butyrate which likely influences colonic uric acid levels $[40,43,70]$. Thus, in particular Prevotellaceae, that mainly determine microbiome differences between PD patients and controls, seem to be related also to urate metabolism, providing ground for further studies.

\section{CONCLUSIONS}

Considering the well established gastrointestinal abnormalities in PD and the vast interactions of gut microbiota with the human host, it seems mandatory to explore whether gut microbiota are involved in this devastating disorder. The recent discovery of gut microbiome alterations in PD is a promising first step, but obviously only a scrape on the surface. Intriguing 
associations have been reported based on which microbiota could indeed play a role at the interface between environmental and lifestyle factors and PD. Figure 1 gives an overview of these possible connections and Table 1 provides a list of the taxa mentioned in this context. However, data about the mechanisms behind these associations and their relevance for PD is scarce. The most promising domains seem to be related to gut barrier function, inflammation, oxidative stress, gut motility, and metabolism. By studying these we may gain more insight into the hugely complex network of microbiome-host-interactions underlying the observed associations. Longitudinal studies integrating metagenomic, transcriptomic, metabolomic, and systems biology approaches with clinical parameters and eventually interventional studies will hopefully elucidate the temporal and mechanistic relationships between established risk modifiers, gut microbiota, and PD.

\section{REFERENCES}

[1] Noyce AJ, Bestwick JP, Silveira-Moriyama L, Hawkes CH, Giovannoni G, Lees AJ, \& Schrag A (2012) Meta-analysis of early nonmotor features and risk factors for Parkinson disease. Ann Neurol, 72, 893-901.

[2] Wirdefeldt K, Adami HO, Cole P, Trichopoulos D, \& Mandel J (2011) Epidemiology and etiology of Parkinson's disease: A review of the evidence. Eur J Epidemiol, 26(Suppl 1), S1-58.

[3] Prediger RD (2010) Effects of caffeine in Parkinson's disease: From neuroprotection to the management of motor and nonmotor symptoms. J Alzheimers Dis, 20 (Suppl 1), S205-S220.

[4] Quik M, Perez XA, \& Bordia T (2012) Nicotine as a potential neuroprotective agent for Parkinson's disease. Mov Disord, 27, 947-957.

[5] Ross GW, \& Petrovitch H (2001) Current evidence for neuroprotective effects of nicotine and caffeine against Parkinson's disease. Drugs Aging, 18, 797-806.

[6] Moco S, Martin FP, \& Rezzi S (2012) Metabolomics view on gut microbiome modulation by polyphenol-rich foods. $J$ Proteome Res, 11, 4781-4790.

[7] Kachroo A, \& Schwarzschild MA (2012) Adenosine A2A receptor gene disruption protects in an alpha-synuclein model of Parkinson's disease. Ann Neurol, 71, 278-282.

[8] Ryan RE, Ross SA, Drago J, \& Loiacono RE (2001) Dose-related neuroprotective effects of chronic nicotine in 6hydroxydopamine treated rats, and loss of neuroprotection in alpha4 nicotinic receptor subunit knockout mice. Br J Pharmacol, 132, 1650-1656.

[9] Tavassoly O, Kakish J, Nokhrin S, Dmitriev O, \& Lee JS (2014) The use of nanopore analysis for discovering drugs which bind to alpha-synuclein for treatment of Parkinson's disease. Eur J Med Chem, 88, 42-54.

[10] Hong DP, Fink AL, \& Uversky VN (2009) Smoking and Parkinson's disease: Does nicotine affect alpha-synuclein fibrillation? Biochim Biophys Acta, 1794, 282-290.

[11] Ritz B, Lee PC, Lassen CF, \& Arah OA (2014) Parkinson disease and smoking revisited: Ease of quitting is an early sign of the disease. Neurology, 83, 1396-1402.
[12] Evans AH, Lawrence AD, Potts J, MacGregor L, Katzenschlager R, Shaw K, Zijlmans J, \& Lees AJ (2006) Relationship between impulsive sensation seeking traits, smoking, alcohol and caffeine intake, and Parkinson's disease. J Neurol Neurosurg Psychiatry, 77, 317-321.

[13] Shen C, Guo Y, Luo W, Lin C, \& Ding M (2013) Serum urate and the risk of Parkinson's disease: Results from a metaanalysis. Can J Neurol Sci, 40, 73-79.

[14] Poewe W (2008) Non-motor symptoms in Parkinson's disease. Eur J Neurol, 15(Suppl 1), 14-20.

[15] Cersosimo MG, \& Benarroch EE (2012) Pathological correlates of gastrointestinal dysfunction in Parkinson's disease. Neurobiol Dis, 46, 559-564.

[16] Forsyth CB, Shannon KM, Kordower JH, Voigt RM, Shaikh M, Jaglin JA, Estes JD, Dodiya HB, \& Keshavarzian A (2011) Increased intestinal permeability correlates with sigmoid mucosa alpha-synuclein staining and endotoxin exposure markers in early Parkinson's disease. PLoS One, 6, e28032.

[17] Devos D, Lebouvier T, Lardeux B, Biraud M, Rouaud T, Pouclet H, Coron E, Bruley des Varannes S, Naveilhan P, Nguyen JM, Neunlist M, \& Derkinderen P (2013) Colonic inflammation in Parkinson's disease. Neurobiol Dis, 50, 42-48.

[18] Braak H, de Vos RA, Bohl J, \& Del Tredici K (2006) Gastric alpha-synuclein immunoreactive inclusions in Meissner's and Auerbach's plexuses in cases staged for Parkinson's diseaserelated brain pathology. Neurosci Lett, 396, 67-72.

[19] Shannon KM, Keshavarzian A, Dodiya HB, Jakate S, \& Kordower JH (2012) Is alpha-synuclein in the colon a biomarker for premotor Parkinson's disease? Evidence from 3 cases. Mov Disord, 27, 716-719.

[20] Kieburtz K, \& Wunderle KB (2013) Parkinson's disease: Evidence for environmental risk factors. Mov Disord, 28, 8-13.

[21] Savica R, Carlin JM, Grossardt BR, Bower JH, Ahlskog JE, Maraganore DM, Bharucha AE, \& Rocca WA (2009) Medical records documentation of constipation preceding Parkinson disease: A case-control study. Neurology, 73, 1752-1758.

[22] Lema Tome CM, Tyson T, Rey NL, Grathwohl S, Britschgi M, \& Brundin P (2013) Inflammation and alpha-synuclein's prion-like behavior in Parkinson's disease-is there a link? Mol Neurobiol, 47, 561-574.

[23] Qin J, Li R, Raes J, Arumugam M, Burgdorf KS, Manichanh C, Nielsen T, Pons N, Levenez F, Yamada T, Mende DR, Li J, Xu J, Li S, Li D, Cao J, Wang B, Liang H, Zheng H, Xie Y, Tap J, Lepage P, Bertalan M, Batto JM, Hansen T, Le Paslier D, Linneberg A, Nielsen HB, Pelletier E, Renault P, Sicheritz-Ponten T, Turner K, Zhu H, Yu C, Li S, Jian M, Zhou Y, Li Y, Zhang X, Li S, Qin N, Yang H, Wang J, Brunak S, Dore J, Guarner F, Kristiansen K, Pedersen O, Parkhill J, Weissenbach J, Consortium MetaHIT, Bork P, Ehrlich SD, \& Wang J (2010) A human gut microbial gene catalogue established by metagenomic sequencing. Nature, 464, 59-65.

[24] Li M, Wang B, Zhang M, Rantalainen M, Wang S, Zhou H, Zhang Y, Shen J, Pang X, Zhang M, Wei H, Chen Y, Lu H, Zuo J, Su M, Qiu Y, Jia W, Xiao C, Smith LM, Yang S, Holmes E, Tang H, Zhao G, Nicholson JK, Li L, \& Zhao L (2008) Symbiotic gut microbes modulate human metabolic phenotypes. Proc Natl Acad Sci U S A, 105, 2117-2122.

[25] Sommer F, \& Backhed F (2013) The gut microbiota-masters of host development and physiology. Nat Rev Microbiol, 11, 227-238.

[26] Abt MC, \& Artis D (2009) The intestinal microbiota in health and disease: The influence of microbial products on immune cell homeostasis. Curr Opin Gastroenterol, 25, 496-502. 
[27] Goldsmith JR, \& Sartor RB (2014) The role of diet on intestinal microbiota metabolism: Downstream impacts on host immune function and health, and therapeutic implications. J Gastroenterol, 49, 785-798.

[28] Nicholson JK, Holmes E, Kinross J, Burcelin R, Gibson G, Jia W, \& Pettersson S (2012) Host-gut microbiota metabolic interactions. Science, 336, 1262-1267.

[29] Kim BS, Jeon YS, \& Chun J (2013) Current Status and Future Promise of the Human Microbiome. Pediatr Gastroenterol Hepatol Nutr, 16, 71-79.

[30] Cryan JF, \& Dinan TG (2012) Mind-altering microorganisms: The impact of the gut microbiota on brain and behaviour. Nat Rev Neurosci, 13, 701-712.

[31] Tillisch K, Labus J, Kilpatrick L, Jiang Z, Stains J, Ebrat B, Guyonnet D, Legrain-Raspaud S, Trotin B, Naliboff B, Mayer EA (2013) Consumption of fermented milk product with probiotic modulates brain activity. Gastroenterology, 144, 1394-1401.e4.

[32] Diaz Heijtz R, Wang S, Anuar F, Qian Y, Bjorkholm B, Samuelsson A, Hibberd ML, Forssberg H, \& Pettersson S (2011) Normal gut microbiota modulates brain development and behavior. Proc Natl Acad Sci U S A, 108, 3047-3052.

[33] Forsythe P, \& Kunze WA (2013) Voices from within: Gut microbes and the CNS. Cell Mol Life Sci, 70, 55-69.

[34] Bercik P, Denou E, Collins J, Jackson W, Lu J, Jury J, Deng Y, Blennerhassett P, Macri J, McCoy KD, Verdu EF, Collins SM (2011) The intestinal microbiota affect central levels of brain-derived neurotropic factor and behavior in mice. Gastroenterology, 141, 599-609, 609.e1-3.

[35] Scheperjans F, Aho V, Pereira PA, Koskinen K, Paulin L, Pekkonen E, Haapaniemi E, Kaakkola S, Eerola-Rautio J, Pohja M, Kinnunen E, Murros K, \& Auvinen P (2015) Gut microbiota are related to Parkinson's disease and clinical phenotype. Mov Disord, 30, 350-358.

[36] Jakobsson HE, Rodriguez-Pineiro AM, Schutte A, Ermund A, Boysen P, Bemark M, Sommer F, Backhed F, Hansson GC, \& Johansson ME (2015) The composition of the gut microbiota shapes the colon mucus barrier. EMBO Rep, 16, 164-177.

[37] Brinkman BM, Becker A, Ayiseh RB, Hildebrand F, Raes J, Huys G, \& Vandenabeele P (2013) Gut microbiota affects sensitivity to acute DSS-induced colitis independently of host genotype. Inflamm Bowel Dis, 19, 2560-2567.

[38] Scher JU, Sczesnak A, Longman RS, Segata N, Ubeda C, Bielski C, Rostron T, Cerundolo V, Pamer EG, Abramson SB, Huttenhower C, \& Littman DR (2013) Expansion of intestinal Prevotella copri correlates with enhanced susceptibility to arthritis. Elife, 2, e01202.

[39] Costello ME, Ciccia F, Willner D, Warrington N, Robinson PC, Gardiner B, Marshall M, Kenna TJ, Triolo G, Brown MA (2014) Intestinal dysbiosis in ankylosing spondylitis. Arthritis Rheumatol, doi: 10.1002/art.38967.

[40] Ou J, Carbonero F, Zoetendal EG, DeLany JP, Wang M, Newton K, Gaskins HR, \& O'Keefe SJ (2013) Diet, microbiota, and microbial metabolites in colon cancer risk in rural Africans and African Americans. Am J Clin Nutr, 98, 111-120.

[41] Hou JK, Abraham B, \& El-Serag H (2011) Dietary intake and risk of developing inflammatory bowel disease: A systematic review of the literature. Am J Gastroenterol, 106, 563-573.

[42] Jeffery IB, \& O'Toole PW (2013) Diet-microbiota interactions and their implications for healthy living. Nutrients, $\mathbf{5}$, 234-252.

[43] Brown CT, Davis-Richardson AG, Giongo A, Gano KA, Crabb DB, Mukherjee N, Casella G, Drew JC, Ilonen J, Knip M, Hyoty H, Veijola R, Simell T, Simell O, Neu J, Wasserfall CH, Schatz D, Atkinson MA, \& Triplett EW (2011)
Gut microbiome metagenomics analysis suggests a functional model for the development of autoimmunity for type 1 diabetes. PLoS One, 6, e25792.

[44] Mejia-Leon ME, Petrosino JF, Ajami NJ, Dominguez-Bello MG, \& de la Barca AM (2014) Fecal microbiota imbalance in Mexican children with type 1 diabetes. Sci Re, 4, 3814.

[45] Derkinderen P, Shannon KM, \& Brundin P (2014) Gut feelings about smoking and coffee in Parkinson's disease. Mov Disord, 29, 976-979.

[46] Hegazi RA, Rao KN, Mayle A, Sepulveda AR, Otterbein LE, \& Plevy SE (2005) Carbon monoxide ameliorates chronic murine colitis through a heme oxygenase 1-dependent pathway. J Exp Med, 202, 1703-1713.

[47] Verschuere S, De Smet R, Allais L, \& Cuvelier CA (2012) The effect of smoking on intestinal inflammation: What can be learned from animal models? J Crohns Colitis, 6, 1-12.

[48] Ben-Horin S, \& Chowers Y (2008) Neuroimmunology of the gut: Physiology, pathology, and pharmacology. Curr Opin Pharmacol, 8, 490-495.

[49] Coulie B, Camilleri M, Bharucha AE, Sandborn WJ, \& Burton D (2001) Colonic motility in chronic ulcerative proctosigmoiditis and the effects of nicotine on colonic motility in patients and healthy subjects. Aliment Pharmacol Ther, 15, 653-663.

[50] Chu KM, Cho CH, \& Shin VY (2013) Nicotine and gastrointestinal disorders: Its role in ulceration and cancer development. Curr Pharm Des, 19, 5-10.

[51] Zuo L, Li Y, Wang H, Wu R, Zhu W, Zhang W, Cao L, Gu L, Gong J, Li N, \& Li J (2014) Cigarette smoking is associated with intestinal barrier dysfunction in the small intestine but not in the large intestine of mice. J Crohns Colitis, 8 , 1710-1722.

[52] Wang H, Zhao JX, Hu N, Ren J, Du M, \& Zhu MJ (2012) Sidestream smoking reduces intestinal inflammation and increases expression of tight junction proteins. World J Gastroenterol, 18, 2180-2187.

[53] Prytz H, Benoni C, \& Tagesson C (1989) Does smoking tighten the gut? Scand J Gastroenterol, 24, 1084-1088.

[54] Benjamin JL, Hedin CR, Koutsoumpas A, Ng SC, McCarthy NE, Prescott NJ, Pessoa-Lopes P, Mathew CG, Sanderson J, Hart AL, Kamm MA, Knight SC, Forbes A, Stagg AJ, Lindsay JO, \& Whelan K (2012) Smokers with active Crohn's disease have a clinically relevant dysbiosis of the gastrointestinal microbiota. Inflamm Bowel Dis, 18, 1092-1100.

[55] Biedermann L, Brulisauer K, Zeitz J, Frei P, Scharl M, Vavricka SR, Fried M, Loessner MJ, Rogler G, \& Schuppler M (2014) Smoking cessation alters intestinal microbiota: Insights from quantitative investigations on human fecal samples using FISH. Inflamm Bowel Dis, 20, 1496-1501.

[56] Alcock J, Maley CC, \& Aktipis CA (2014) Is eating behavior manipulated by the gastrointestinal microbiota? Evolutionary pressures and potential mechanisms. Bioessays, 36, 940-949.

[57] Boekema PJ, Samsom M, van Berge Henegouwen GP, \& Smout AJ (1999) Coffee and gastrointestinal function: Facts and fiction. A review. Scand J Gastroenterol Suppl, 230, $35-$ 39.

[58] Brown SR, Cann PA, \& Read NW (1990) Effect of coffee on distal colon function. Gut, 31, 450-453.

[59] Murakami K, Okubo H, \& Sasaki S (2006) Dietary intake in relation to self-reported constipation among Japanese women aged 18-20 years. Eur J Clin Nutr, 60, 650-657.

[60] Gniechwitz D, Reichardt N, Blaut M, Steinhart H, \& Bunzel M (2007) Dietary fiber from coffee beverage: Degradation by human fecal microbiota. J Agric Food Chem, 55, 6989-6996. 
[61] Jaquet M, Rochat I, Moulin J, Cavin C, \& Bibiloni R (2009) Impact of coffee consumption on the gut microbiota: A human volunteer study. Int J Food Microbiol, 130, 117-121.

[62] Nakayama T, \& Oishi K (2013) Influence of coffee (Coffea arabica) and galacto-oligosaccharide consumption on intestinal microbiota and the host responses. FEMS Microbiol Lett, 343, 161-168.

[63] Faust K, Sathirapongsasuti JF, Izard J, Segata N, Gevers D, Raes J, \& Huttenhower C (2012) Microbial co-occurrence relationships in the human microbiome. PLoS Comput Biol, 8, e1002606.

[64] Khokhlova EV, Smeianov VV, Efimov BA, Kafarskaia LI, Pavlova SI, \& Shkoporov AN (2012) Anti-inflammatory properties of intestinal Bifidobacterium strains isolated from healthy infants. Microbiol Immunol, 56, 27-39.

[65] Zhu L, Liu W, Alkhouri R, Baker RD, Bard JE, Quigley EM, $\&$ Baker SS (2014) Structural changes in the gut microbiome of constipated patients. Physiol Genomics, 46, 679-686.

[66] Khalif IL, Quigley EM, Konovitch EA, \& Maximova ID (2005) Alterations in the colonic flora and intestinal permeability and evidence of immune activation in chronic constipation. Dig Liver Dis, 37, 838-849.

[67] Kim SE, Choi SC, Park KS, Park MI, Shin JE, Lee TH, Jung KW, Koo HS, Myung SJ, Constipation Research group of Korean Society of Neurogastroenterology, Motility (2015) Change of fecal flora and effectiveness of the short-term VSL\#3 probiotic treatment in patients with functional constipation. J Neurogastroenterol Motil, 21, 111-120.

[68] Kashyap PC, Marcobal A, Ursell LK, Larauche M, Duboc H, Earle KA, Sonnenburg ED, Ferreyra JA, Higginbottom SK, Million M, Tache Y, Pasricha PJ, Knight R, Farrugia G, \& Sonnenburg JL (2013) Complex interactions among diet, gastrointestinal transit, and gut microbiota in humanized mice. Gastroenterology, 144, 967-977.

[69] Lim MY, Rho M, Song YM, Lee K, Sung J, \& Ko G (2014) Stability of gut enterotypes in Korean monozygotic twins and their association with biomarkers and diet. Sci Rep, 4, 7348.

[70] Hamer HM, Jonkers DM, Bast A, Vanhoutvin SA, Fischer MA, Kodde A, Troost FJ, Venema K, \& Brummer RJ (2009)
Butyrate modulates oxidative stress in the colonic mucosa of healthy humans. Clin Nutr, 28, 88-93.

[71] Crane JK, \& Mongiardo KM (2014) Pro-inflammatory effects of uric acid in the gastrointestinal tract. Immunol Invest, $\mathbf{4 3}$, 255-266.

[72] Eckburg PB, Bik EM, Bernstein CN, Purdom E, Dethlefsen L, Sargent M, Gill SR, Nelson KE, \& Relman DA (2005) Diversity of the human intestinal microbial flora. Science, 308, 1635-1638.

[73] Queipo-Ortuno MI, Seoane LM, Murri M, Pardo M, GomezZumaquero JM, Cardona F, Casanueva F, \& Tinahones FJ (2013) Gut microbiota composition in male rat models under different nutritional status and physical activity and its association with serum leptin and ghrelin levels. PLoS One, 8 , e65465.

[74] Kang DW, Park JG, Ilhan ZE, Wallstrom G, Labaer J, Adams JB, \& Krajmalnik-Brown R (2013) Reduced incidence of Prevotella and other fermenters in intestinal microflora of autistic children. PLoS One, 8, e68322.

[75] Kunze WA, Mao YK, Wang B, Huizinga JD, Ma X, Forsythe P, \& Bienenstock J (2009) Lactobacillus reuteri enhances excitability of colonic AH neurons by inhibiting calciumdependent potassium channel opening. J Cell Mol Med, 13, 2261-2270.

[76] Bienenstock J, Gibson G, Klaenhammer TR, Walker WA, \& Neish AS (2013) New insights into probiotic mechanisms: A harvest from functional and metagenomic studies. Gut Microbes, 4, 94-100.

[77] De Angelis M, Piccolo M, Vannini L, Siragusa S, De Giacomo A, Serrazzanetti DI, Cristofori F, Guerzoni ME, Gobbetti M, \& Francavilla R (2013) Fecal microbiota and metabolome of children with autism and pervasive developmental disorder not otherwise specified. PLoS One, 8, e76993.

[78] Ventura M, Turroni F, Lugli GA, \& van Sinderen D (2014) Bifidobacteria and humans: Our special friends, from ecological to genomics perspectives. J Sci Food Agric, 94, 163-168. 